\title{
REFLEXÃO
}

\section{VENHA VER O PÔR DO SOL: CONSIDERAÇÕES SOBRE A EXPERIÊNCIA DO SILÊNCIO NA FORMAÇÃO ARTÍSTICA}

Regina Machado ${ }^{1}$

Para Amina Shah

Então antigamente a gente ia ver o pôr do sol. Quer dizer, não que as pessoas saíssem de casa com essa intenção, tipo um programa. O pôr do sol acontecia, e acontece, todos os dias, cada dia diferente do anterior. Geralmente coincidia com o fim do trabalho, e nessa hora parada o pôr do sol estava ali, acessível, no horizonte. É que havia horizonte. Se não da porta da minha casa, com três passos se chegava num lugar onde seria possível descortinar o encontro do céu com a terra, ou com a montanha, ou com o mar e acompanhar o sol sumindo, sumindo. Todo dia.

Hoje, por trás dos prédios - cortinas irremovíveis - das nossas cidades, o sol continua se pondo cada dia de um jeito, num horizonte que ninguém consegue saber se existe, quanto mais ver. Criança de hoje não conhece a expressão: " ter horizonte na vida". Porque não tem a experiência do horizonte, não pode entender a expressão. Simples assim? Será que uma pessoa pode ser "alguém com horizonte na vida", se não vive a experiência possivelmente cotidiana, e não apenas turística, de contemplar no silêncio do fim da tarde a nunca mesmice de um pôr de sol?

"Até que nem tanto esotérico assim"...

Essa experiência tem a ver com um certo ritmo, com uma cadência respiratória, com o alargamento dos acreditados limites do existir, com o pouso numa quietude de onde pode emergir o que ainda não é. Que poderá manifestar-se depois em turbulência, ruptura, denúncia, dor, tanto faz. Falo do silêncio não como alienação e sim como condição de gestação do porvir.

"De onde vem o baião, vem debaixo do barro do chão...."

Essa experiência também remete a um certo estado da Arte, urdido nessa substância de encontro do dia com a noite, na hora preferida do Leonardo da Vinci. 
Lembro:

Da primeira leitura que fiz do conto $O$ Espelho de Machado de $\mathrm{Assis}^{2}$. O encontro com a Arte da Palavra a desenrolar pouco a pouco uma idéia narrativa feita de conjuntos de qualidades: dos espaços, dos personagens, dos ritmos dos diálogos, do tempo do enunciado. Tudo isso entretecido no ritmo da respiração, da intenção de Machado de Assis. O conto ia se formando dentro de mim enquanto entrava em contato com as mais diversas qualificações/pulsações da sequência narrativa. Resumindo o assunto: numa sala pequena, à noite, quatro homens de idade madura discutiam "questões de alta transcendência" enquanto um quinto personagem permanecia calado. Depois de muito tempo de falações metafísicas, solicitado a dar sua opinião, o homem quieto conta um caso que aconteceu com ele quando era jovem.

Lembro da última frase do texto do Machado de Assis: "Quando os outros voltaram a si, o narrador havia descido as escadas"3. O homem quieto, o Jacobina, silenciou os argumentos, a discussão, o discurso de convencimento, a altercação: a estória que contou foi seu silêncio. Ele se retirou para que o conto falasse e não ele. O autor, Machado de Assis, também silenciou o que ia ser o desfecho que seu texto habilidosamente preparou .

Foi quando li essa frase que o estado da Arte se instalou em mim. No silêncio devastador que se impôs, como um grande espaço de alargamento dos limites do meu existir, como uma chave de compreensão, como o encontro do texto com algo dentro da minha pessoa. Uma espécie de susto, uma revelação, um vislumbre. Produziu-se uma experiência de significação. Equivalente, imagino, ao impacto que silenciou os debatedores e os deixou "no espelho", ensimesmados no efeito que a história de carne e osso produziu em cada um deles. Ressonância que se espelhou em mim, ao ler a última frase da forma artística criada pelo Machado de Assis, grande mestre na arte de soprar silêncios no ar.

Esse silêncio/ressonância/encontro/significação é fundamental na experiência de contato com a Arte. Quando a gente compreende alguma coisa que faz sentido, então a vida faz sentido, mesmo que a gente não saiba qual. A gente compreende, mesmo às vezes sem entender, porque a obra conversa com um repertório interno de perguntas, percepções, conhecimentos, inquietações próprios a uma pessoa, particularmente. 
Então, de um lado está a "genialidade" da obra, a perícia do artista, a qualidade estética capaz de provocar algum estado na gente. De outro lado, alguém que pode conversar com essa rede de qualidades e estar disponível para essa conversa. Conversa que pode produzir uma experiência de significação que é ao mesmo tempo experiência de pertencimento, em que o encontro comigo mesmo, com o outro, com a vida, aponta para uma centelha que acende meus olhos. Que é também uma experiência de harmonia: por um instante a unidade da obra provoca uma ordenação caleidoscópica que acorda minha integridade humana, mesmo que ela esteja, digamos, soterrada. Experiência que se dá no silêncio da contemplação, na disposição interna de receber, de escutar, de permitir o encontro da obra com minha história pessoal e a surpreendente aprendizagem que esse encontro me traz, no assombro, no mistério: produzindo em mim indagações e maravilhamentos a me assegurar de que o sentido da vida vale a pena ser buscado.

Trata-se aqui de um assunto: o ensino e a aprendizagem da Arte. Penso particularmente na aprendizagem da literatura, oral ou escrita, tanto faz. Penso de propósito na Arte da Palavra como parte desse conjunto de Formas Artísticas que compõem os currículos escolares, de modo em geral tão engavetados. Parece que a literatura está sempre numa gaveta separada, ligada à área do ensino de Língua Portuguesa, difícil encontrá-la ao lado das Artes Visuais, do Teatro, da Música, da Dança. No entanto, não se esqueçam: tudo o que eu disser daqui para frente inclui muito enfaticamente o ensino e aprendizagem da Arte da Palavra.

Há educadores artistas e alunos. Crianças, jovens e adultos. Formas, elementos e princípios de formatividade. Procedimentos, técnicas, materiais e critérios de avaliação. Processos e caminhos de aprender. Por onde começar?

Então na Arte existe uma condição, um estado de contemplação do horizonte, o estado de conceber, de arquitetar diversos desenhos, de sondar combinações de imagens. Como podemos criar situações de contato (nosso) e dos alunos com esse silêncio que é espaço de gestação em meio à balbúrdia do nosso tempo? Como propiciar o contato e o alargamento desse universo repertório de imagens internas no diálogo com a Arte? Se o nosso objeto de estudo é a Arte, o processo de aprender/ensinar Arte não poderia ser semelhante ao processo de criação/recepção que se manifesta no domínio artístico? Inspirado na experiência que temos, no que vivemos em contato com a Arte? Por que submeter o processo de ensino e 
aprendizagem da Arte a modelos e esquemas construídos em outros domínios, por exemplo o domínio da Pedagogia?

Se o artista silencia o discurso da explicação, por que os educadores artistas não podem fazer o mesmo? Já pensou se o Machado de Assis resolvesse explicar que o caso do Jacobina foi tão bem contado que deixou os outros sem palavras? Se ele inventou sua última frase surpresa, não seria uma boa idéia para nós usarmos também com os alunos a surpresa?

Lembro :

Do conto $A$ sopa de pedra do Pedro Malasartes ${ }^{4}$. Ensaio uma leitura "subversiva". O Pedro Malasartes pode ser, nessa leitura, o educador artista. A velha - que muitos avaliam como "avarenta, xexelenta, mão de vaca, lazarenta, não dá nada pra ninguém" 5 - pode ser um aluno, numa aula de arte. Pergunto: Por que a velha/aluno entregaria seus tesouros, assim, sem mais nem menos, para fazer uma sopa/um trabalho criador/ uma escuta/ um olhar para uma obra de arte / um assunto de aprender. A avareza é nessa metáfora um resguardo, um gesto cauteloso de abrir a cortina para ver o que está acontecendo lá fora, do outro lado da janela. Como se a velha/aluno dissesse: no que isso me diz respeito?

Malasartes, o educador artista, faz então um convite. Sem dizer nenhuma palavra. Um convite à curiosidade, à percepção da velha/aluno : e se fosse possível existir uma sopa de pedra?

“Santa curiosidade! Tu não és só a alma da civilização, és também o pomo da concórdia, fruta divina..."6.

Será que essa pedra que ele deposita na água fervendo não seria a possibilidade bruta/a condição para o fazer, escutar, ver, pensar, realizar uma experiência de contato com a arte? Ele sabe o que quer, mas não sabe qual a sopa que vai sair. Não traz uma sopa Knorr pronta para oferecer, não traz todos os ingredientes. Mas ele sabe o que é uma sopa, substância que já fez e tomou várias vezes. Que é, nesse caso, quente, feita no fogo, dentro de um recipiente, é nutritiva, leva tempo para cozinhar. Ele tem a experiência do assunto, o propósito desenhado, as questões, os vários tipos de conhecimentos necessários.

Então, o que ele faz é primeiro "convocar a sensibilidade" (na expressão de uma aluna minha de pós-graduação, Ana Carolina Pinheiro) da velha/aluno. Começando por convocar a curiosidade para o que ainda não é, mas pode vir a ser. Em nome do que pode vir a ser, a velha/aluno começa a trazer seus tesouros: o que 
ela tem de precioso, guardado atrás da janela, dentro da sua casa. Sua cebola, seu tomate, toucinho, suas imagens internas, seu conhecimento de si mesma, dos outros e do mundo, seus medos, descobertas, confusões, sua vontade de aprender.

Fico achando que a sabedoria do Malasartes /educador artista está, antes de mais nada, nesse silencioso dispor de situações de aprendizagem como "convocações da sensibilidade" da velha/aluno. Ele chama e autoriza esses tesouros de cada um de seus alunos. Assegura que todos esses interiores são bem-vindos. E aqui também o silêncio é muito importante. Às vezes se entende motivar como convencer, e dá-lhe falação. Querer, como numa espécie de missão autoimposta, "levar o aluno a ..." nessa hora pode ser fatal. Penso que esse é o primeiro passo: essa entrega para algo que faz sentido buscar - quero ver do que se trata essa tal de sopa de pedra/Arte.

Do que se trata essa sopa de pedra/Arte? Da concepção, das percepções e da produção de qualidades configuradas em formas artísticas segundo certos princípios e contextos particulares a cada época histórica e cultural. Então é para essas qualidades que posso aprender a dirigir minha atenção. Penso que se trata, antes de qualquer outra coisa, de acordar a percepção. Perceber é distinguir qualidades. Porque qualificar é entrar em contato com o que dá sentido, essencialmente, a tudo que existe. Já faz muito tempo, Rudolph Arnheim ${ }^{7}$ disse que deveríamos, os educadores artistas, propor desafios perceptivos para nossos alunos, e não estímulos sensoriais, dos quais, diga-se de passagem, o inferno aqui na terra está cheio...

Pedra dura, áspera, lisa, pesada, no meio do caminho tinha uma pedra. No meio do meu caminho tem uma pedra pequena, enorme, removível, intransponível, ridícula, que me faz sentir raiva. De repente, pedra vira nuvem. Nossa, como foi que isso aconteceu? Transformação. Quando a velha tomou a sopa, o que se transformou dentro dela - penso que isso é que é importante. Que gosto tem essa sopa? Tudo é exercício de percepção. Que começa no contato com o barro debaixo do chão. No silêncio desse espaço.

Senão na contemplação do pôr do sol - que aqui é quase apenas metáfora - ao menos na disposição de situações equivalentes, onde o horizonte aponta para além dele, a pedra aponta para o gosto que pode ter a sopa. Situação de observação de possibilidades, na quietude dentro da gente. 
Da janela, a velha vê o Malasartes fazendo seu foguinho, colocando sobre ele sua panela com água e... uma pedra. Não há pressa, há o estabelecimento de um contato, de uma provocação. Não há: "quero que você aprenda isso e mais isso, conteúdos $x$, y e z." Há: a intenção que carrega a pergunta silenciosa: " e se você trouxesse $x, y$ e $z$, por algo que vale a pena?" A sopa só pode ser feita se você trouxer sua percepção, sua imaginação, sua intuição, seu pensamento, sua afetividade, sua pessoa. $O$ trabalho do educador artista não seria orquestrar a forma dessa sopa? Para que afinal seja sopa e não qualquer coisa, uma "criatividade" saída da "imaginação" do aluno, que legal?

O que seria então orquestrar?

Como educadores artistas muitas vezes já tivemos a experiência desse poder milenar do que num certo momento da história do ocidente passamos a chamar de Arte. O poder de atravessar como uma flecha certeira os consumidos desejos de felicidade, fazendo a gente ficar com vontade de acreditar que pode existir um ser humano melhor, mais íntegro e mais corajoso. Mesmo o artista mais cético, por que se daria ao trabalho de realizar uma obra, se não fosse no mínimo movido por um desejo de contribuir para alguma mudança?

Como educadores artistas, além dos planejamentos, objetivos e crenças pedagógicas, está, eu penso, a lembrança de nossos próprios encontros, em silêncio, com a Arte que nos transforma. Então, enraizados nessa boniteza, (era Paulo Freire quem falava da boniteza de ensinar e aprender $)^{8} \mathrm{em}$ vez de buscarmos mastros em nossa função de "ensinar" talvez a gente possa se perguntar: como trazer, para nosso encontro com a Arte e com nossos alunos, esse horizonte, esse estado de horizonte no pôr do sol, onde a terra se encontra com o céu, o dia cessa e a noite ainda não germinou, algo se aquieta para dar lugar ao que vai chegar, tempo de não ação, que alguns diriam, de oração?

Se... o que captura tentacularmente a atenção das crianças, presas horas a fio na teia de aranha dos joguinhos de computador, reduzidas que ficam a dedinhos e olhos ágeis, seria bom, quem sabe, a gente começar nosso trabalho diário com nossos alunos convocando ritmos, movimentos de corpo inteiro - canto, dança, música, cantigas - considerando essa ação como conteúdo da aula? Como conceber essa ação para que de fato ela seja artística e não ginástica? Como trabalhar as qualidades das formas com cada grupo diferente de alunos? Como escutar a ilusória impossibilidade de uma criança quando ela diz que não sabe 
desenhar? Como sugerir a escuta de um bosque? Como convidar à contemplação/observação de algo equivalente a um pôr de sol no horizonte? Como encontrar dentro da gente o profundo amor que o Machado de Assis tem pelo ser humano a ponto de guiar sua mão e sua literatura para buscar sua alma por dentro da farda do alferes?

O profundo amor que guia a mão do Malasartes, mexendo a sopa de pedra e apostando no derretimento da pedra dentro da velha avarenta.

\section{NOTAS}

${ }^{1}$ Regina Machado é professora livre-docente na Escola de Comunicações e Artes da Universidade de São Paulo, e doutora em Artes. Publicou, entre outras obras, os livros Acordais: fundamentos teóricopoéticos da arte de contar histórias (DCL, 2004) e O violino cigano e outros contos de mulheres sábias (Cia. das Letras, 2004).

${ }^{2}$ ASSIS, Machado de. Obra Completa. Rio de Janeiro: Nova Aguilar, 1994. v II.

${ }^{3}$ Idem, p. 352.

${ }^{4}$ Conto da tradição oral ibérica e brasileira. (N.E.).

${ }^{5}$ Frase ritmada criada por Estevão Marques para sua narração oral desse conto.

${ }^{6}$ Machado de Assis, no conto citado, p. 347.

${ }^{7}$ ARNHEIM, Rudolf. Intuição e intelecto na arte. São Paulo, Martins Fontes, 1989.

${ }^{8}$ FREIRE, Paulo: Pedagogia da autonomia. São Paulo: Paz e Terra, 1996, p. 38. 